Proc. Indian Acad. Sci. (Earth Planet. Sci.), Vol. 89, Numbcr 2, July 1980, pp. 261-266.

(C) Printed in India.

\title{
Magnetic studies on charnockites of Palni Hills
}

\author{
K RAMASWAMY and N RAMAMURTHY \\ Department of Physics, Annamalai University, Annamalainagar 608 101, India \\ MS received 17 December 1978 ; revised 10 April 1980

\begin{abstract}
The magnetic properties like coercive force, mean mass susceptibility and relative remanence of some charnockites of Palni Hills, South India collected at
\end{abstract} \\ different altitudes were measured.
}

Keywords. Charnockites; coercive force; mean mass susceptibility; relative remanence.

\section{Introduction}

The study of magnetic behaviour of rocks has evinced keen interest since it throws light on the various features like the constituents, the petrological aspects, the domain structures forming the rock and also the origin and nature of formation. Such studies on the basaltic formation of Deccan traps (Verma et al 1974), columnar basalts of Bombay (Radhakrishnamurthy et al 1971) and North Pacific deep sea sediments (Johnson et al 1975) have been made. One of the interesting formations in South India is the charnockite formations of Tamil Nadu. Systematic studies of the magnetic properties of the charnockite formations of Tamil Nadu area appear to be meagre and this paper attempts to fill this lacuna with special reference to those of Palni Hills.

\section{Petrology and location of charnockites}

Charnockite is the name given to a series of granitoid rocks of South India found in the hill formations of Nilgiris, Palnis, Shevaroys and Pallavaram of Tamil Nadu. These rocks are identified as one of the oldest formations in the world (Wadia 1975). The charnockites of South India have been classified as igneous rocks by Ramaswamy and Murthy (1974) from the optical mineralogical studies. Saxena (1977) pointed out that the mineral, chemical and phase equilibrium relationships indicate that these rocks are formed by recrystallization between $600-900^{\circ} \mathrm{C}$ relatively at shallow depths of 6 to $12 \mathrm{~km}$ and there is a possibility of geothermal gradient of 70 to $100^{\circ} \mathrm{C}$ per $\mathrm{km}$. Further, he suggested that the latest geothermal gradient is around $1300 \times 10^{6}$ years ago. 
Palni Hills has a wide distribution of charnockites at various altitudes. The specimens for the study of the magnetic behaviour were collected at $850-2400 \mathrm{~m}$ altitude with the help of the Geology Department, Annamalai University.

\section{Experimental methods}

To study the magnetic behaviour of rock specimens, an apparatus based on the design of Blackett (1956) and modified by Rakshit and Dutt (1971) was constructed.

In this method, the specimen in the form of a rectangular block was allowed to vibrate between the pole pieces of a homogeneous electromagnet. A pair of pick-up coils wound round the pole pieces picked the a.c. voltage generated during the flux delinking, produced by the vibration of the specimen. This a.c. voltage was rectified and measured by an accurate nanoammeter specially constructed for this purpose. The specimen was partially demagnetised using an a.c. field, to remove any stray magnetism existing in the specimen. Varying the current in the electromagnet, the usual current cycle was followed and a hysteresis loop was drawn. Normally all the specimens tended to get saturated around 2500 Oersted. However, to ensure saturation the field was increased upto 4000 Oersteds. From the hysteresis curves various parameters like the coercive force $H_{0}$, remanent magnetisation $J_{r}$, saturation magnetisation $J_{s}$ and mean mass susceptibility $\chi$ values were obtained. The induced magnetic moment $M$ (in c.g.s. units) of the specimen was calculated using the relation $M=i \times K$ where $K(=15 \cdot 07)$ is the instrument constant obtained from the known parameters of the experimental set-up and $i$ is the current read by the nanoammeter in microamperes.

\section{Results and discussion}

\subsection{Coercive force $H_{0}$}

The coercive force values of the specimens obtained from the hysteresis curves are shown in table 1 . The specimens can be classified into intermediate and acid charnockites on the basis of thin section analysis. Data for grain size and percentage of magnetite, found by means of modal analysis, are also presented in table 1. It is seen that the intermediate rocks appear to have lower values (mean value 240 Oes) for coercive force than the acid rocks (mean value 287 Oes). The coercive force is also found to be inversely proportional to the grain size. The variation is more pronounced in acid rocks compared to the intermediate rocks. A similar pattern has been reported by Nagata (1961) for igneous rocks and by Rakshit (1974) for Rajmahal basalts. Such a behaviour is also consistent with the multidomain structure of magnetite found in these specimens as indicated by modal analysis.

\subsection{Susceptlibility}

The value of mean mass susceptibility has been found to vary from 0.6 to $3 \times 10^{-3}$ e.m.u./g in the charnockite specimens studied. Nagata (1961), after investigating 


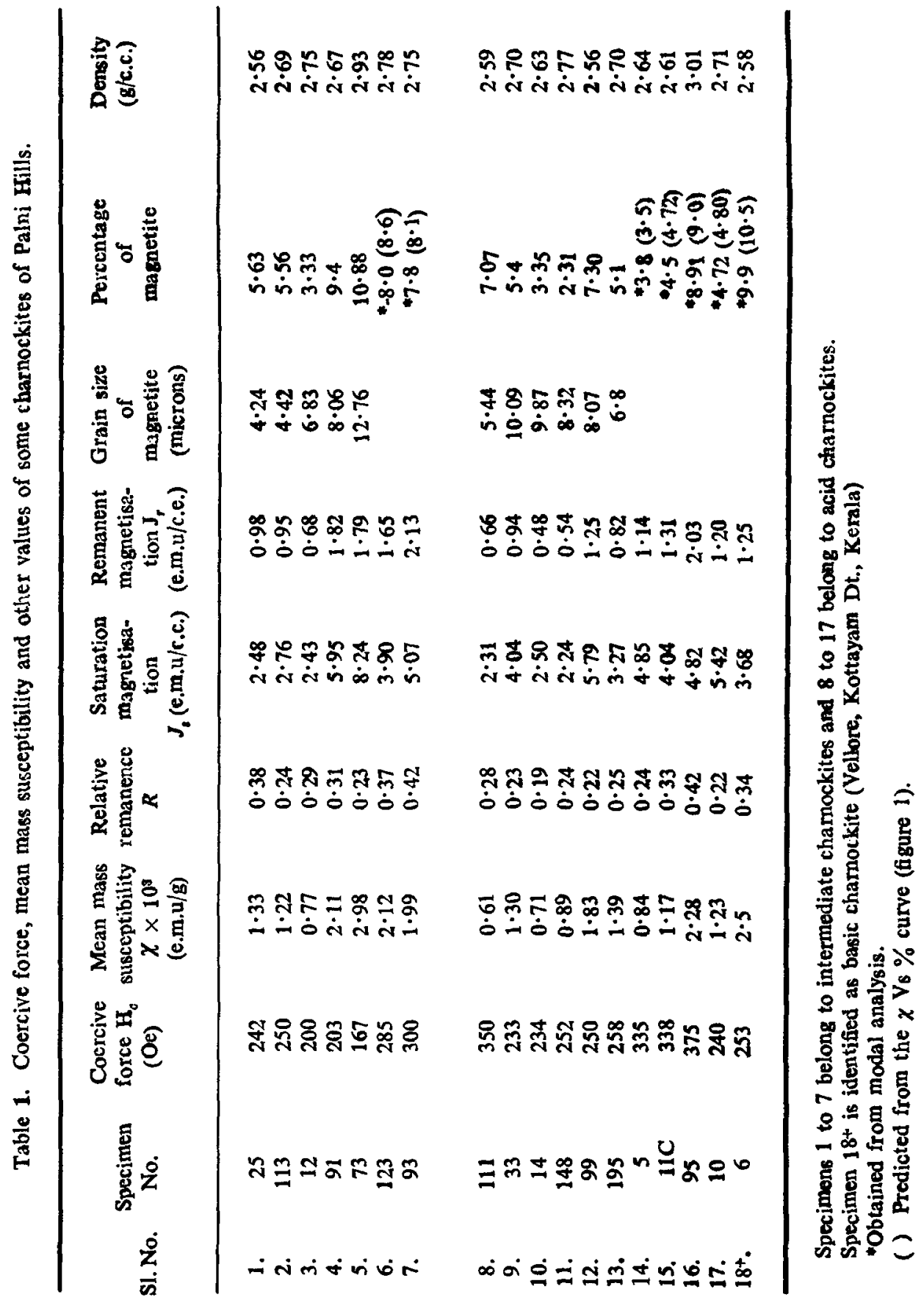


a number of specimens, concluded that in volcanic rocks, $\chi$ is usually in the range from $10^{-4}$ to $10^{2}$ e.m.u./c.c., in plutonic igneous rocks $10^{-4}$ to $5 \times 10^{-3}$ e.m.u./c.c., in metamorphic rocks from $10^{-5}$ to $3 \times 10^{-4}$ e.m.u./c.c. and in sedimentary rocks below $10^{-5}$ e.m.u./c.c. Our values are well within the ranges quoted by Nagata for igneous rocks and this suggests that these rocks may be of igneous origin, as proposed by Ramaswamy and Murthy (1974).

It is a known fact that the susceptibility depends on the percentage of magnetite present in a specimen. An attempt is made to correlate the percentage of magnetite with the $\chi$-values. A linear relationship of the form $\chi=(2.43 \pm 0.20) \times 10^{-2} C_{N t}$ is found to exist (figure 1). Here, $C_{\mathbf{v} t}$ is the norm or theoretically calculated percentage of magnetite. Such a relationship was reported by Nagata (1961) in the case of igneous rocks. For some specimens, the predicted values agree well with the values obtained from the modal analysis (table 1). It is seen from figure 1 that some points are spread from the median line. This spread may be attributed to the fact that the susceptibility is strongly influenced by the size and shape of the grains as well as by their internal stress at the time of formation of the rock (Kato 1940; Balakrishna and Vijayaraghava 1963).

\subsection{Relative remanence $R$ or $J_{s} / J_{s}$ ratio}

Relative remanence $R$ i.e. the ratio of remanent magnetisation $J_{\mathrm{r}}$ to the peak intensity of magnetisation $J_{t}$ for each specimen was calculated and the values given in table 1 indicate that all specimens exhibit $R$ values less than $0 \cdot 5$. One noteworthy feature is that the intermediate charnockite specimens have an average $R$ value of 0.33 while acid specimens have a value around 0.26 .

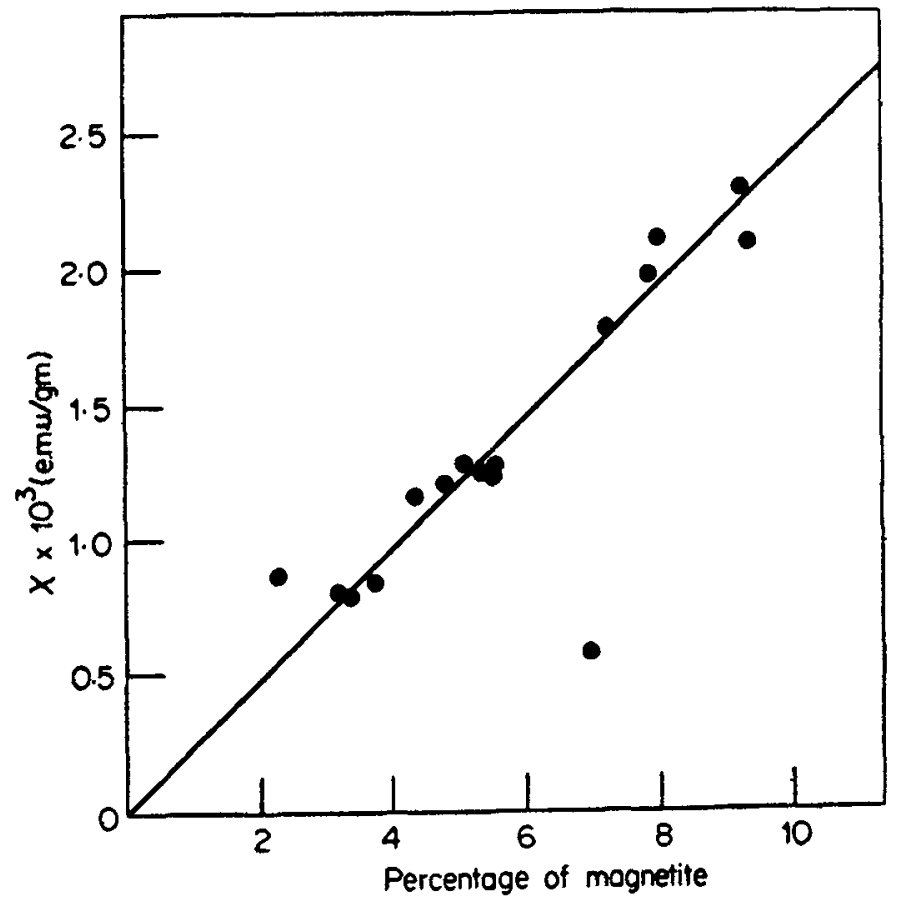

Figure 1. Relation between mass susceptibility and percentage of magnetite. 


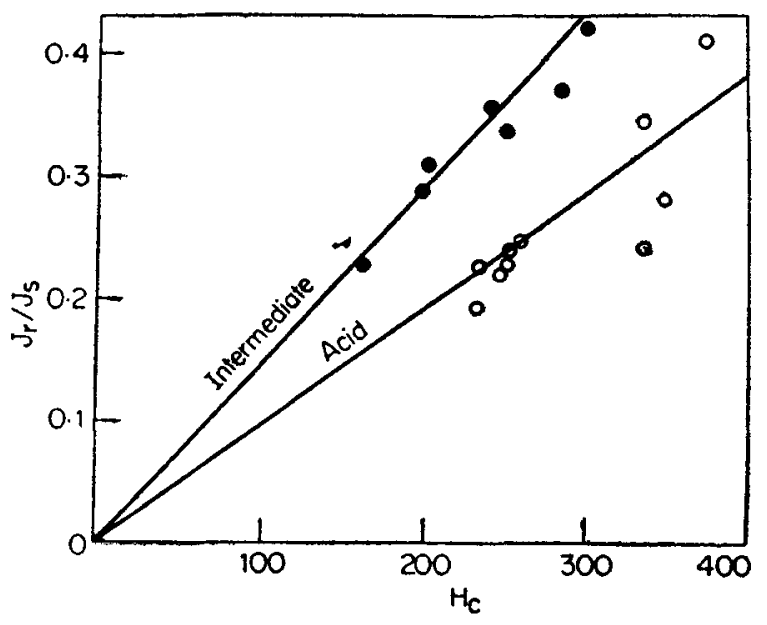

Figure 2. Variation of $J_{r} / J_{s}$ with the coercive force $H_{c}$.

Many authors have discussed the $R$ value in terms of domain structures (Stoner and Wohlfarth 1948; Neel 1955; Johnson et al 1975; Radhakrishamurthy et al 1978). They have stated that $R$ value close to 0.5 indicates single domain grains in rock specimens. Johnson et al (1975) after investigating the magnetic behaviour of some specimens from North Pacific deep sea reported that since these specimens show a value less than 0.5 , multidomain structures are common in these specimens. Radhakrishnamurthy et al (1978) made granulometric analysis of a number of basalt specimens and concluded that $R$ values less than 0.5 indicate a mixture of S-D and M-D grains while $R$ values close to 0.5 indicate the presence of a large percentage of $S-D$ grains.

It may be inferred from the magnitude of $R$ values that all specimens have a mixture of S-D and $M-D$ grains and that the intermediate rocks (mean $R=0.33$ ) have more predominance of S-D grains than the acid rocks (mean $R=0 \cdot 26$ ).

Relative remanence is found to show a linear variation with the coercive forco (fi rure 2). A similar relationship was reported by Nagata (1961).

\section{Conclusions}

The mean value of the coercive force for the charnockites of Palni Hills is found to be equal to 260 Oersteds. $J_{v} / J_{*}$ is less than 0.50 ; this indicates that charnockites contain mixture of S-D and $M-D$ structure of magnetite crystals.

\section{References}

Balakrishna S and Vijayaraghava M S 1963 Bull. Natl. Geophy. Res. Inst. 141 Blackett P M S 1956 Lectures on rock magnetism (Israel : Weizmann Science Press) 
Johnson H P, Kinoshita H and Merril R T 1975 Geol. Soc. Am. Bull. 86412

Kato Y 1940 Rep. Tohoku Imp. Univ. 29629

Nagata T 1943 Bull. Earthq. Res. Inst. p. 21

Nagata T 1961 Rock magnetism (Tokyo: Maruzen Company)

Neel L 1955 Adv. Phys. 4191

Radhakrishnamurthy C, Likhite S D, Raja P K S and Sahasrabudhe P W 1971 Nature Phys. Sci. 23533

Radhakrishnamurthy C, Likhite S D, Deutsch E R and Murthy G S 1978 Proc. Indian Acad. Sci. (Earth Planet. Sci.) A87 235

Ramaswamy A and Murthy M S 1974 Mineral Mag. 39807

Rakshit A K 1974 Acta Ciene. Indica 1153

Rakshit A K and Dutt S K 1971 PAGEOPH. 92 (XI) 133

Saxena S K 1977 Science 198614

Stoner E C and Wohlfarth E P 1948 Philos. Trans. Soc. A240 599

Verma R K, Mital G S and Bhalla M S 1974 Geophys. Res. Bull. 1237

Wadia D A 1975 Geology of India (New Delhi : Tata McGraw-Hill) 